\title{
Synthesis and Characterization of Anatase Titanium Dioxide Nanoparticles Using Egg White Solution via Sol-Gel Method
}

\author{
Samira Bagheri, ${ }^{1}$ Kamyar Shameli, ${ }^{1,2}$ and Sharifah Bee Abd Hamid ${ }^{1}$ \\ ${ }^{1}$ Centre for Research in Nanotechnology \& Catalysis (NANOCEN), University of Malaya, IPS Building, 50603 Kuala Lumpur, Malaysia \\ ${ }^{2}$ Department of Chemistry, Faculty of Science, Universiti Putra Malaysia, 43400 Serdang, Selangor, Malaysia
}

Correspondence should be addressed to Samira Bagheri; samira_bagheri@siswa.um.edu.my

Received 22 September 2012; Revised 8 October 2012; Accepted 23 October 2012

Academic Editor: Fabio Finocchi

Copyright (c) 2013 Samira Bagheri et al. This is an open access article distributed under the Creative Commons Attribution License, which permits unrestricted use, distribution, and reproduction in any medium, provided the original work is properly cited.

\begin{abstract}
Anatase titanium dioxide nanoparticles (TNPs) are synthesized by a simple and cost-effective process with and without freshly water-soluble egg white proteins (albumin) via sol-gel method. The main advantage of using egg white proteins as a gelling agent is that it can provide long-term stability for nanoparticles by preventing particles agglomeration. The X-ray diffraction and FTIR results indicate that the synthesized nanoparticles have only the anatase structure without the presence of any other phase impurities. Additionally, the TNPs are characterized by a number of techniques such as thermogravimetric analysis (TGA), Xray diffraction analysis (XRD), transmission electron microscopy (TEM), Fourier transform infrared spectroscopy (FTIR), and ultraviolet visible spectra (UV-vis). The sizes of titanium dioxide nanoparticles with and without using egg white solution are $12.55 \pm 3.42 \mathrm{~nm}$ and $21.45 \pm 4.21 \mathrm{~nm}$, respectively. The results indicate that egg white solution is a reliable and cheap green gelling agent that can be used as a matrix in the sol-gel method to synthesis tiny size TNPs.
\end{abstract}

\section{Introduction}

Recently, titanium dioxide $\left(\mathrm{TiO}_{2}\right)$ has proven to be one of the promising $n$-type semiconductors because of its wide band gap $(3.2 \mathrm{eV})$ under ultraviolet light [1]. In addition, having high physical and chemical stability as well as high refractive index makes this material widely researched $[2,3]$. Due to its optical and electronic properties, it can be used in several fields such as photocatalyst, solar cells, sensors, self-cleaning, and bactericidal action [4-6].

Three types of crystallographic structures have been discovered for titanium dioxide including anatase (tetragonal), rutile (tetragonal), and brookite (orthorhombic). Among the structures, rutile is the most stable one while anatase and brookite are metastable phases at ambient temperature. However, due to the large surface area per unit mass and volume, anatase appears to have the highest photocatalytic activity compared to the others [7]. The anatase crystal itself also presents a finer transparency under near ultraviolet compared to rutile [8]. Furthermore, the low crystal lattice packing fraction causes anatase crystal to have low hardness and reduces its refractive indices. Therefore, it is preferable in some applications.

Numerous methods were introduced to synthesize TNPs. Some researchers suggest the microemulsion method due to its short processing time [9]. By using the physical vapor deposition (PVD) method, materials are condensed after evaporated to form solid [10]. Other methods such as hydrolysis [11] and hydrothermal [12, 13] have been used in many studies. As for sol-gel method, the materials undergo hydrolysis and polycondensation processes to form the sol and then gel will be formed after aging or gelation and eventually become solid crystals after drying. This can be a simple method as it requires low temperature and controllable final product properties [14-16].

The small size of titanium dioxide nanoparticles can be obtained by using an appropriate gelling agent in the solgel method. Egg white proteins (albumin) are famous for their gelling, foaming, and emulsifying characteristics, in addition to their high nutrition quality [17-19]. Because of its solubility in water and its ability to associate with metal ions in solution, egg white has been used as a binder cum 
gel forming material in forming the shape of porous ceramics and bulks [20-22].

In this study a simple, costeffective, and environment friendly synthesis introduced to synthesize anatase TNPs by using water-soluble egg white proteins as a gelling agent via sol-gel method. The gelling agent will help to control the nanoparticles size and dispersion due to the expansion during calcination. Furthermore, the surface morphology and size of the anatase titanium dioxide nanoparticles were identified and analyzed by using different apparatus.

\section{Experimental Procedures}

2.1. Preparation of Anatase $\mathrm{TiO}_{2}$ Nanoparticles. Sample A as a precursor solution to synthesis TNPs without using egg white solution was prepared when titanium (IV) isopropoxide (98\%, Acros Organics) was dissolved in the glacial acetic acid (100\%, Merck), it acts as a catalyst to prevent titanium isopropoxide from the nucleophilic's attacks by the water [23] and deionised water $(18.2 \mathrm{M} \Omega \mathrm{cm})$ with the molar ratio of $1: 10: 200$. The solution was stirred for several hours and dried at about $80^{\circ} \mathrm{C}$ overnight. The dried gel was grinded and calcined in a muffle furnace at $500^{\circ} \mathrm{C}$ for 5 hours. To synthesize sample B of TNPs with egg white solution, the precursor solution was prepared as above mentioned. Freshly water-soluble egg white proteins $(30 \mathrm{~mL})$ were homogenized in water $(100 \mathrm{~mL})$ by stirring on a magnetic stirrer. Then, the egg white solution was added dropwise into the precursor solution. The solution was continued to be heated and stirred at about $80^{\circ} \mathrm{C}$ for 5 hours. The result solution was then dried in the oven at $80^{\circ} \mathrm{C}$ overnight. The dried crystal was grinded and calcined at $500^{\circ} \mathrm{C}$ for 5 hours.

2.2. Characterization of $\mathrm{TiO}_{2}$ Nanoparticles. The dried fine gel of synthesized $\mathrm{TiO}_{2}$ was subjected to thermogravimetric analysis (TGA) (Mettler Toledo TGA/SDTA 851e) in order to measure the thermal stability of the materials. Bruker-D8 Advance Powder X-ray diffraction (XRD) was used to determine the crystal phase identification and estimate the crystallite size. To measure the particle size and morphology of TNPs, transmission electron microscopy (TEM), LEO-Libra 120 and scanning electron microscopy (SEM), and Zeiss Supra 35VP were used. Fourier transform infrared spectroscopy (FTIR) studies were carried out in the $400-4000 \mathrm{~cm}^{-1}$ frequency range. For the infrared absorption spectra, the samples were formed into pellets with $\mathrm{KBr}$ and the spectra were recorded on a BRUKER FTIR Spectrometer. IR spectroscopy in the transmission mode gives qualitative information about the way in which the adsorbed molecules are bonded to the surfaces as well as the structural information of solids. For UV-visible absorption spectrum, samples were dispersed in distilled water and sonicated ultrasonically for the absorption studies on a Mettler Toledo spectrophotometer.

\section{Results and Discussion}

In this study, egg white solution was applied as a stabilizer and gelling agent for reducing agglomeration of nanoparticles.
Water-soluble proteins of egg white forms a matrix of entangled polymeric chains, inside the cavities of which can trap small volumes of metal ions. During heat treatment, the dried precursors decompose into nanocrystalline products. The schematic illustration of TNPs' synthesis by using egg white solution is depicted schematically in Figure 1.

3.1. Thermogravimetric Analysis (TGA). Figure 2((a) and (b)) shows the TGA curves of TNPs' sample A and B. According to the curve (a) in Figure 2, sample A experienced two main step downs through the TGA test. The first weight loss happened at about $105^{\circ} \mathrm{C}$ due to the water evaporation. The second mass loss occurred at $105^{\circ} \mathrm{C}-340^{\circ} \mathrm{C}$ which is due to the volatilization and combustion of organic species such as $\mathrm{CH}_{3} \mathrm{COOH}$ [24]. There is no associated signal with these latter thermal events in the TGA curve confirming the crystallization and phase transition events.

TGA curve of the TNPs synthesized using egg white solution. Sample B is presented in curve (b) of Figure 2. This curve descends until it becomes horizontal around $450^{\circ} \mathrm{C}$. TGA curve of sample B experienced three main step downs through the TGA test. The first weight loss between 50 and $110^{\circ} \mathrm{C}$ is an initial loss of water. The second weight loss starts from 110 to $255^{\circ} \mathrm{C}$ that is related to the decomposition of the chemically bound and last weigh reduction is between 255 and $450^{\circ} \mathrm{C}$ due to decomposition of organic groups and albumin. No weight loss between 450 and $900^{\circ} \mathrm{C}$ was detected on the TGA curve, which indicates the formation of nanocrystalline $\mathrm{TiO}_{2}$. TGA curve reveals that the proteins were removed by heating process to burn out the organics in air.

3.2. Powder X-Ray Diffraction (XRD). Figure 3((a) and (b)) shows the XRD patterns of samples A and B of TNPs. The XRD peaks in the wide angle range of $2 \theta\left(20^{\circ}<2 \theta<\right.$ $90^{\circ}$ ) ascertained that the peaks in $25.367^{\circ}, 37.053^{\circ}, 37.909^{\circ}$, $38.667^{\circ}, 48.158^{\circ}, 54.051^{\circ}, 55.204^{\circ}, 62.867^{\circ}, 68.976^{\circ}, 70.479^{\circ}$, $75.303^{\circ}$, and $82.926^{\circ}$ can be attributed to the 101,103 , $004,112,200,105,211,204,116,220,215$, and 224 crystalline structures of anatase synthesized TNPs, respectively, (Anatase XRD JCPDS Card no. 78-2486).

The crystallite size $(D)$ can be determined by the Scherrer's formula $(D=K \lambda /(\beta \cos \theta))$. $\lambda$ is the wavelength of $\mathrm{X}$ ray radiation $(\mathrm{CuK} \alpha=0.15406 \mathrm{~nm}), K$ is a constant taken as $0.89, \beta$ is the line width at half maximum height (FWHM) of the peak, and $\theta$ is the diffracting angle. The (101) plane was chosen to calculate the crystalline size (either plane can be used for this purpose). The average crystalline size for the TNPs synthesized with and without using egg white solution is approximately $11 \mathrm{~nm}$ to $18 \mathrm{~nm}$, respectively.

3.3. Transmission Electron Microscopy (TEM). $\mathrm{TiO}_{2}$ nanoparticles were dispersed in distilled water and sonicated ultrasonically. Then, they were dropped cast on a copper grid of TEM. Figures 4(a) and 4(b) show morphology and size distribution of TNPs' samples A and B. The size histograms of the TNPs are shown beside the relative TEM images. The histograms show that the main particle size of samples A and B of TNPs were about $21.45 \pm 4.21 \mathrm{~nm}$ and $12.55 \pm 3.42 \mathrm{~nm}$, respectively. 


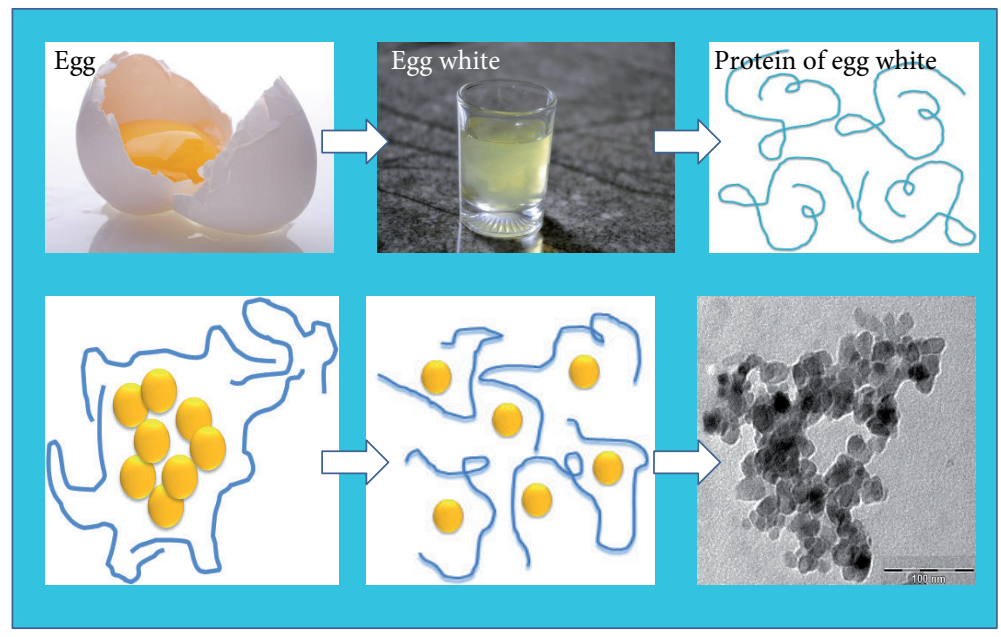

FIGURE 1: Schematic illustration showing how protein of egg white prevents agglomeration of nanoparticles.

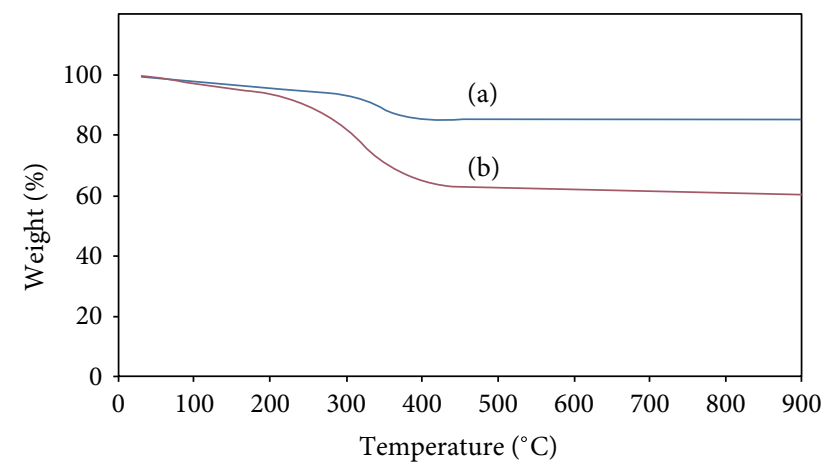

FIGURE 2: TGA curves for samples $\mathrm{A}$ and $\mathrm{B}$ of TNPs from room temperature to $900^{\circ} \mathrm{C}((\mathrm{a})$ and (b)).

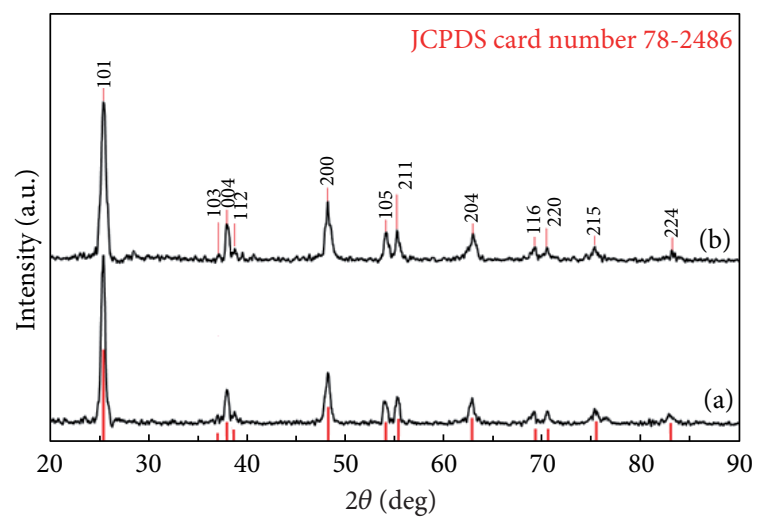

Figure 3: X-ray diffraction patterns for samples A and B of TNPs ((a) and (b)).

3.4. Fourier Transform Infrared Spectroscopy (FTIR). Figure 5((a) and (b)) shows the spectra of TNPs' of samples A and $\mathrm{B}$ of which were synthesized via sol-gel method in the range of $400-4000 \mathrm{~cm}^{-1}$. In Figure 5, curve (b) is for sample B of synthesized TNPs by using egg white solution. In this curve, peaks at $485 \mathrm{~cm}^{-1}$ and $732 \mathrm{~cm}^{-1}$ are for
$\mathrm{O}-\mathrm{Ti}-\mathrm{O}$ bonding in anatase morphology $[25,26]$. The bands centered at $1621 \mathrm{~cm}^{-1}$ and $3354 \mathrm{~cm}^{-1}$ are the characteristic of surface-adsorbed water and hydroxyl groups [25]. Curve (a) in Figure 5 shows sample A of TNPs. The peaks at $479 \mathrm{~cm}^{-1}$ and $652 \mathrm{~cm}^{-1}$ are contributions of the anatase TNPs [27]. The peaks centred at $1627 \mathrm{~cm}^{-1}$ at $3388 \mathrm{~cm}^{-1}$ are the characteristic of $\delta-\mathrm{H}_{2} \mathrm{O}$ bending and vibration of hydroxyl groups [26]. There is no peak at $2900 \mathrm{~cm}^{-1}$ for curve (a) and (b) of TNPs regarding $\mathrm{C}-\mathrm{H}$ stretching band, which means all organic compounds were removed from the samples after calcinations.

3.5. UV-Visible Absorption Spectrum. Figure 6((a) and (b)) shows the UV-vis absorption spectra for samples A and B of TNPs between 300 and $800 \mathrm{~nm}$. Sample A has got a peak in $380 \mathrm{~nm}$ and sample B has got a peak in $371 \mathrm{~nm}$. It is clear that as the size of particles decreases, peaks become sharper and the absorbance increases in the sample which was synthesized by using egg white solution. The blue shift is ascribed to the decrease in crystallite size.

The band gap energy $(E)$ was calculated as per the literature report [28] using the following equation:

$$
\text { Band gap energy }(E)=\frac{h c}{\lambda}
$$

where $h$ is the Planks constant, $6.626 \times 10^{-34} \mathrm{Js}, c$ is the speed of light, $3.0 \times 10^{8} \mathrm{~m} / \mathrm{s}$ and $\lambda$ is the wavelength $(\mathrm{nm})$. According to this equation the bandgap of sample A is $3.2 \mathrm{eV}$ and the bandpag of sample $B$ is $3.3 \mathrm{eV}$, and these results confirm that when the size is smaller, the bandgap will be bigger.

A smaller particle size means a larger band gap, since fewer molecular orbitals are being added to the possible energy states of the particle. Hence, absorption will occur at higher energies, so a shift towards shorter wavelengths will be apparent. 

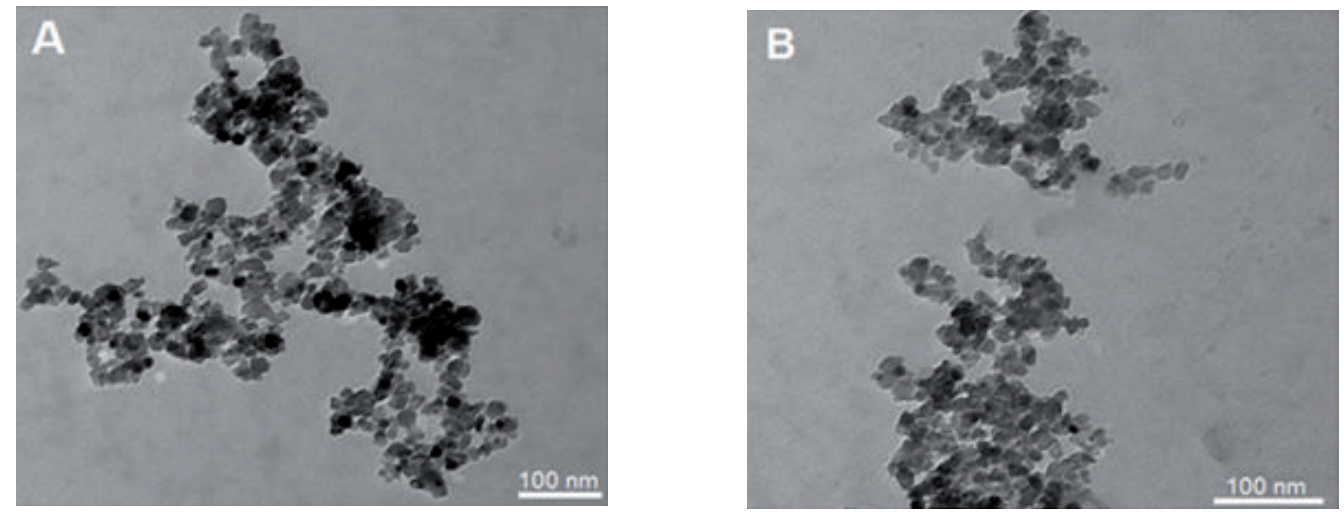

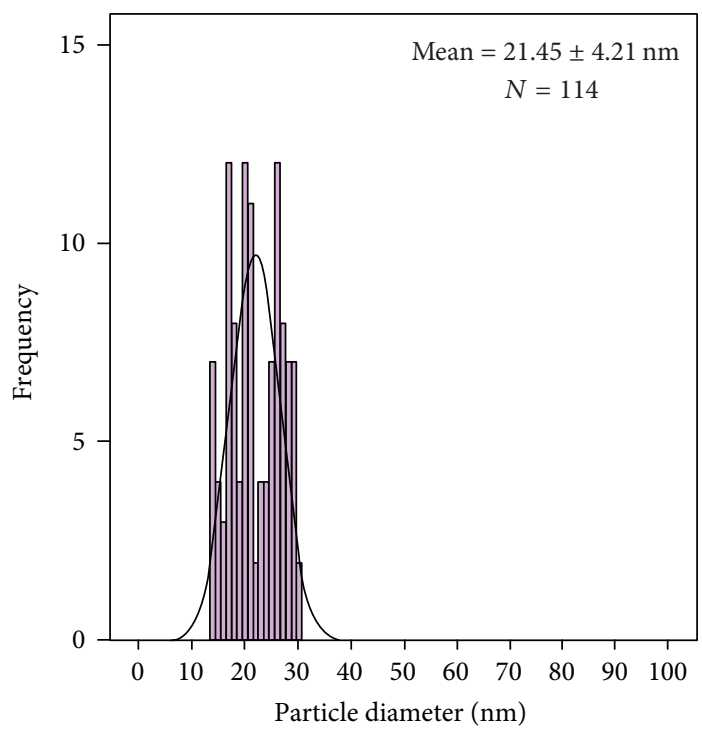

(a)

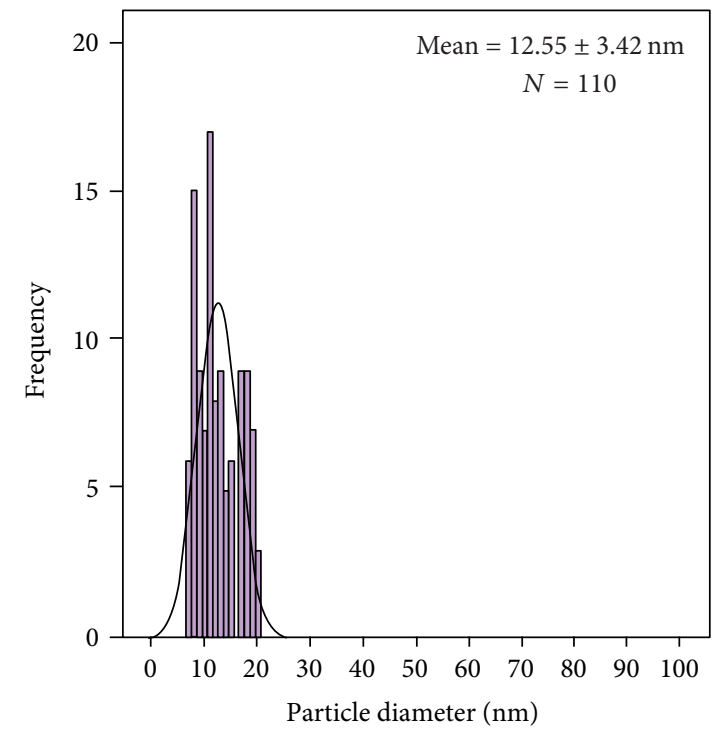

(b)

FIGURE 4: Transmission electron microscopy images and the particle size distributions for samples A and B of TNPs ((a) and (b)).

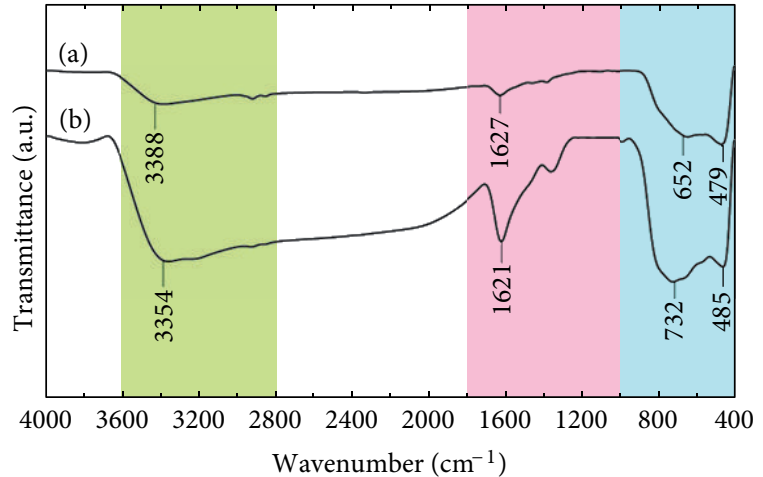

FIGURE 5: Fourier transform infrared spectra for samples A and B of TNPs ((a) and (b)).

\section{Conclusion}

Anatase TNPs were synthesized with and without watersoluble egg white proteins (albumin) by the sol-gel method. From XRD and FTIR results, it is clear that synthesized TNPs exhibited the anatase structure. TEM and XRD results

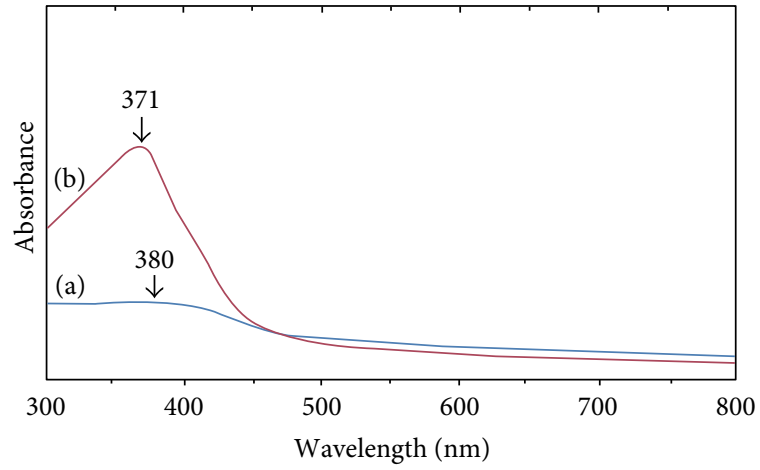

FIgURE 6: The Ultraviolet visible spectra for samples A and B of TNPs ((a) and (b)).

indicate that using egg white solution as a matrix improves the crystallinity and decreases the size of particles. The particle sizes of the TNPs, with and without egg white solution were $12.55 \pm 3.42 \mathrm{~nm}$ and $21.45 \pm 4.21 \mathrm{~nm}$, respectively. Watersoluble proteins of egg white forms a matrix of entangled polymeric chains, inside the cavities of which can trap small 
volumes of metal ions. During heat treatment, the dried precursors decompose into nanocrystalline products. The results confirm that egg white solution is an appropriate gelling agent for synthesising TNPs by using sol-gel method. The current simple, cost-effective and environmental friendly synthesis method using water-soluble egg white proteins can be extended to prepare fine particles of other interesting materials.

\section{Acknowledgment}

This work was supported by the University of Malaya through Grant no. PV 128/2012A.

\section{References}

[1] A. Zaleska, "Doped- $\mathrm{TiO}_{2}$ : a review," Recent Patents on Engineering, vol. 2, no. 3, pp. 157-164, 2008.

[2] Y. Xie, Y. Qian, Y. Zhong, H. Guo, and Y. Hu, "Facile low-temperature synthesis of carbon nanotube $/ \mathrm{TiO}_{2}$ nanohybrids with enhanced visible-light-driven photocatalytic activity," International Journal of Photoenergy, vol. 2012, Article ID 682138, 6 pages, 2012.

[3] F. Sayilkan, M. Asiltürk, H. Sayilkan, Y. Önal, M. Akarsu, and E. Arpaç, "Characterization of $\mathrm{TiO}_{2}$ synthesized in alcohol by a sol-gel process: the effects of annealing temperature and acid catalyst," Turkish Journal of Chemistry, vol. 29, no. 6, pp. 697-706, 2005.

[4] R. Gómez, T. López, E. Ortiz-Islas et al., "Effect of sulfation on the photoactivity of $\mathrm{TiO}_{2}$ sol-gel derived catalysts," Journal of Molecular Catalysis A, vol. 193, no. 1-2, pp. 217-226, 2003.

[5] U. Yogeswaran and S. M. Chen, "A review on the electrochemical sensors and biosensors composed of nanowires as sensing material," Sensors, vol. 8, no. 1, pp. 290-313, 2008.

[6] K. K. Gupta, M. Jassal, and A. K. Agrawal, "Sol-gel derived titanium dioxide finishing of cotton fabric for self cleaning," Indian Journal of Fibre and Textile Research, vol. 33, no. 4, pp. 443-450, 2008.

[7] S. Chaturvedi, P. N. Dave, and N. K. Shah, "Applications of nano-catalyst in new era," Journal of Saudi Chemical Society, vol. 16, no. 3, pp. 307-325, 2012.

[8] F. Cardarelli, Materials Handbook: A Concise Desktop Reference, 2nd edition, 2008.

[9] Z. Liu, Z. Jian, J. Fang, X. Xu, X. Zhu, and S. Wu, "Lowtemperature reverse microemulsion synthesis, characterization, and photocatalytic performance of nanocrystalline titanium dioxide," International Journal of Photoenergy, vol. 2012, Article ID 702503, 8 pages, 2012.

[10] X. Chen and S. S. Mao, "Titanium dioxide nanomaterials: synthesis, properties, modifications and applications," Chemical Reviews, vol. 107, no. 7, pp. 2891-2959, 2007.

[11] M. Lal, V. Chhabra, P. Ayyub, and A. Maitra, "Preparation and characterization of ultrafine $\mathrm{TiO}_{2}$ particles in reverse micelles by hydrolysis of titanium di-ethylhexyl sulfosuccinate," Journal of Materials Research, vol. 13, no. 5, pp. 1249-1254, 1998.

[12] R. R. Basca and M. Gratzel, "Rutile formation in hydrothermally crystallized nanosized titania," Journal of the American Ceramic Society, vol. 79, no. 8, pp. 2185-2188, 1996.

[13] T. R. N. Kutty, R. Vivekanandan, and P. Murugaraj, "Precipitation of rutile and anatase $\left(\mathrm{Tio}_{12}\right)$ fine powders and their conversion to $\mathrm{MTiO}_{3}(\mathrm{M}=\mathrm{Ba}, \mathrm{Sr}, \mathrm{Ca})$ by the hydrothermal method," Materials Chemistry and Physics, vol. 19, no. 6, pp. 533-546, 1988.

[14] L. K. Campbell, B. K. Na, and E. I. Ko, "Synthesis and characterization of titania aerogels," Chemistry of Materials, vol. 4, no. 6, pp. 1329-1333, 1992.

[15] A. V. Prasada Rao, A. I. Robin, and S. Komarneni, "Bismuth titanate from nanocomposite and sol-gel processes," Materials Letters, vol. 28, no. 4-6, pp. 469-473, 1996.

[16] D. F. Vieira and A. Pawlicka, "Optimization of performances of gelatin/ $\mathrm{LiBF}_{4}$-based polymer electrolytes by plasticizing effects," Electrochimica Acta, vol. 55, no. 4, pp. 1489-1494, 2010.

[17] D. V. Vadehra, K. R. Nath, and R. Forsythe, "Eggs as a source of protein," CRC Critical Reviews in Food Technology, vol. 4, no. 2, pp. 193-309, 1973.

[18] E. Li-Chen and S. Nakai, "Biochemical basis for the properties of egg white," CRC Critical Reviews in Poultry Biology, vol. 2, no. 1, pp. 21-59, 1989.

[19] Y. Mine, "Recent advances in the understanding of egg white protein functionality," Trends in Food Science \& Technology, vol. 6, no. 7, pp. 225-232, 1995.

[20] O. Lyckfeldt, J. Brandt, and S. Lesca, "Protein forming-a novel shaping technique for ceramics," Journal of the European Ceramic Society, vol. 20, no. 14-15, pp. 2551-2559, 2000.

[21] S. Dhara and P. Bhargava, "Egg white as an environmentally friendly low-cost binder for gelcasting of ceramics," Journal of the American Ceramic Society, vol. 84, no. 12, pp. 3048-3050, 2001.

[22] S. Dhara and P. Bhargava, "A simple direct casting route to ceramic foams," Journal of the American Ceramic Society, vol. 86, no. 10, pp. 1645-1650, 2003.

[23] S. Doeuff, M. Henry, C. Sanchez, and J. Livage, "Hydrolysis of titanium alkoxides: modification of the molecular precursor by acetic acid," Journal of Non-Crystalline Solids, vol. 89, no. 1-2, pp. 206-216, 1987.

[24] R. Parra, M. S. Góes, M. S. Castro, E. Longos, P. R. Bueno, and J. A. Varela, "Reaction pathway to the synthesis of anatase via the chemical modification of titanium isopropoxide with acetic acid," Chemistry of Materials, vol. 20, no. 1, pp. 143-150, 2008.

[25] G. Soler-Illia, A. Louis, and C. Sanchez, "Synthesis and characterization of mesostructured titania-based materials through evaporation-induced self-assembly," Chemistry of Materials, vol. 14, no. 2, pp. 750-759, 2002.

[26] J. C. Yu, L. Z. Zhang, Z. Zheng, and J. C. Zhao, "Synthesis and characterization of phosphated mesoporous titanium dioxide with high photocatalytic activity," Chemistry of Materials, vol. 15, no. 11, pp. 2280-2286, 2003.

[27] K. E. Karakitsou and X. E. Verykios, "Effects of altervalent cation doping of $\mathrm{TiO}_{2}$ on its performance as a photocatalyst for water cleavage," Journal of Physical Chemistry, vol. 97, no. 6, pp. 1184-1189, 1993.

[28] J. Dharma and A. Pisal, UV/Vis/NIR Spectrometer, Perkin Elmer Application Notes. 

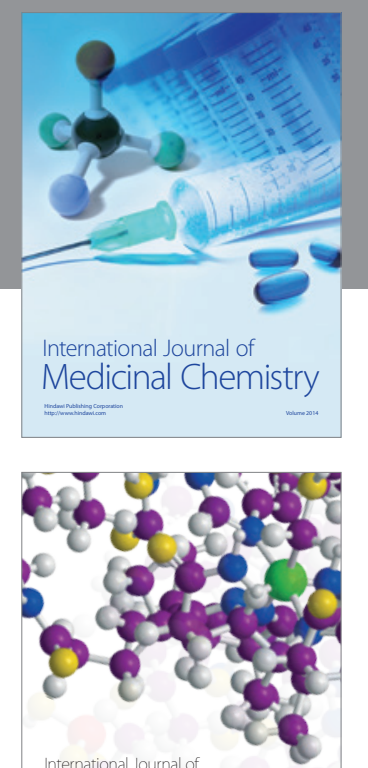

\section{Carbohydrate} Chemistry

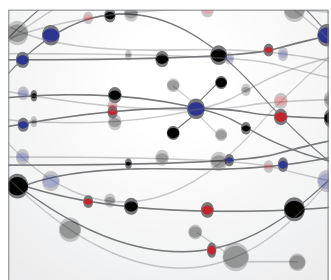

The Scientific World Journal
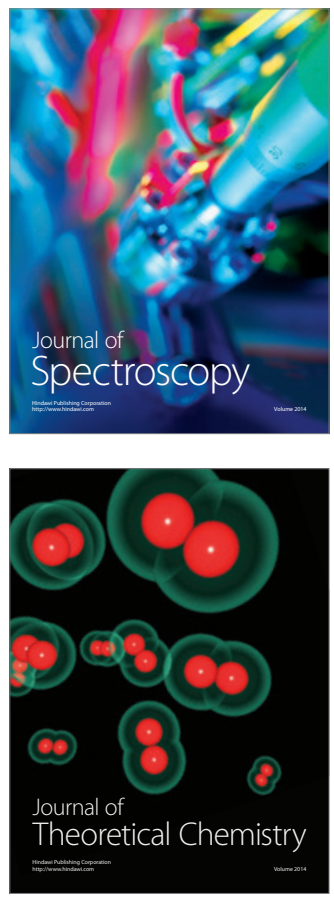
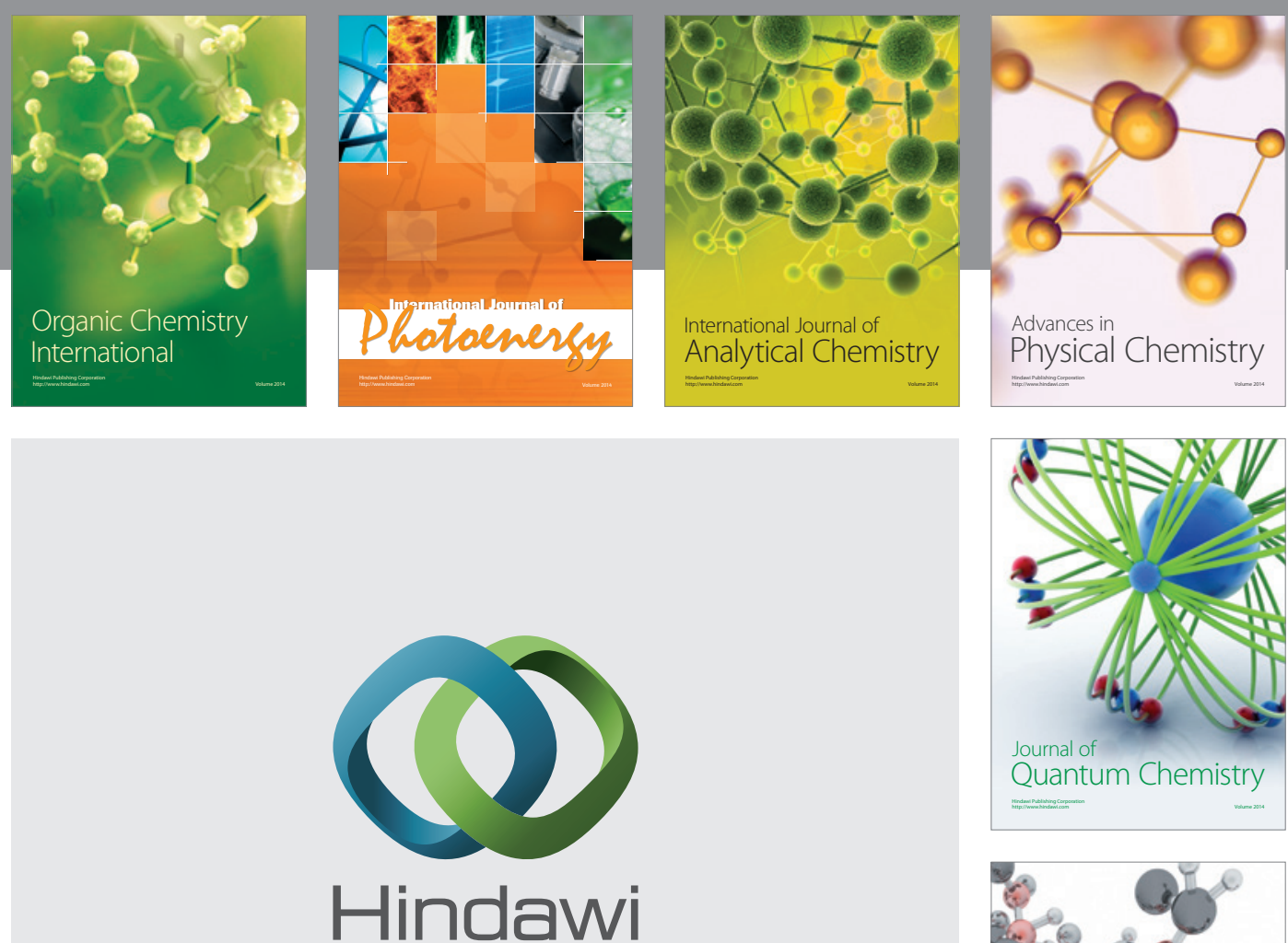

Submit your manuscripts at

http://www.hindawi.com

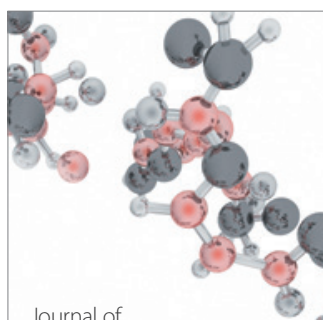

Analytical Methods

in Chemistry

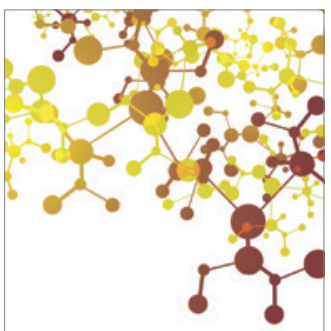

Journal of

Applied Chemistry

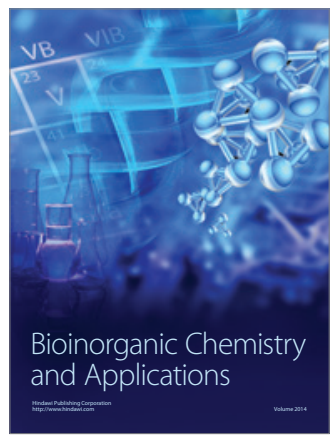

Inorganic Chemistry
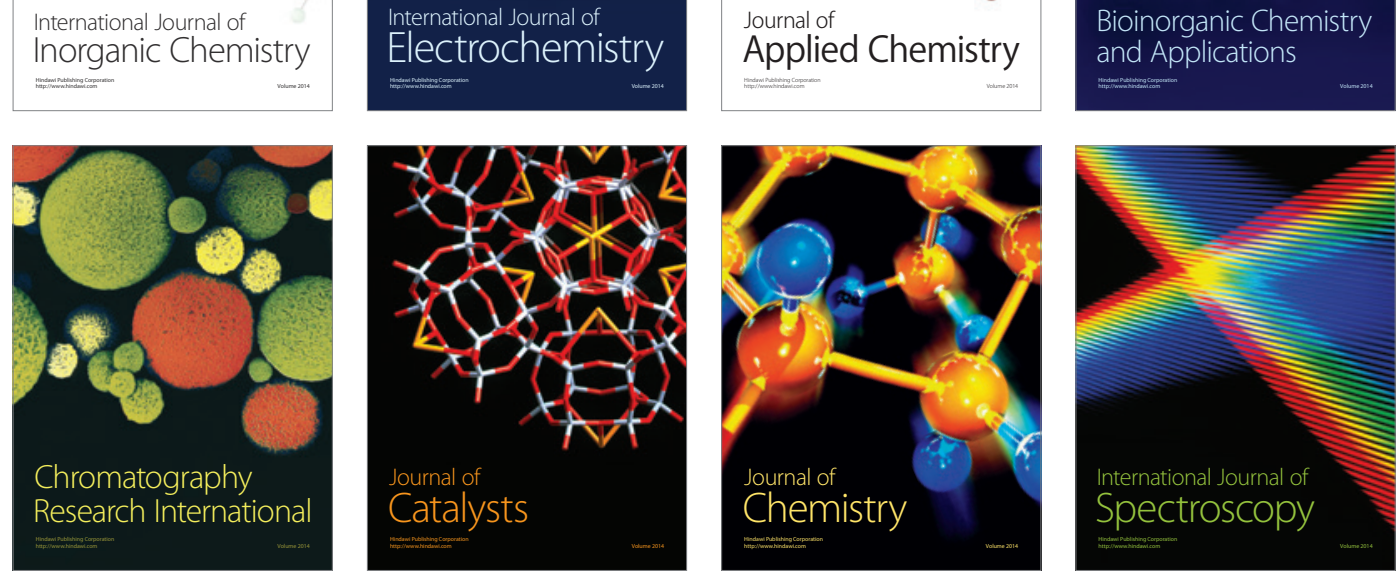